\title{
NICOLÁS DE CUSA, ENTRE TOMÁS DE AQUINO Y DUNS ESCOTO. LA DEFENSA DE LA METAFÍSICA CREACIONISTA MEDIEVAL FRENTE A LA POSTMODERNIDAD. (A TRAVÉS DE INCIARTE-LLANO Y HOFF)
}

Nicholas of Cusa, between Thomas Aquinas and Duns Scotus. The defense of the medieval creationist metaphysics against postmodernism. (Through Inciarte-Llano and Hoff).

\author{
Carlos Ortiz de Landázuri \\ Universidad de Navarra
}

\section{RESUMEN}

Se reconstruye el debate posmoderno iniciado por Heidegger respecto de la posibilidad de una metafísica creacionista que pudiera superar la diferencia última intransitable entre los «ente» y el correspondiente «ser de los entes», al modo propuesto por Inciarte-Llano y Johannes Hoff. Ambos defienden la propuesta de síntesis formulada por Nicolás de Cusa entre la postura tomista y escotista respecto de la metafísica de la creación, ya sea en nombre de un principio de plenitud o de analogía. A este respecto, ambas propuestas resultan internamente complementarias, aunque se formulan desde presupuestos muy diferentes.

Palabras clave: analogía, diferencia, entidad, individuación.

\begin{abstract}
This article reconstructs the postmodern debate initiated by Heidegger about the possibility of a creationist metaphysics that could overcome the last impassable difference between «being» and the corresponding «being of entities», in the manner proposed by Inciarte-Llano and Johannes Hoff. Both defend the proposal synthesis made by Nicholas of Cusa between the Thomist and Scotist positions on the metaphysics of creation, on behalf of a principle of either plenitude or analogy. In this regard, both proposals are internally complementary, but are made from very different presuppositions.
\end{abstract}

Key words: analogy, difference, entity, individuation.

\section{INTRODUCCIÓN: EL DEBATE SOBRE EL FINAL DE LA METAFÍSICA CREACIONISTA MEDIEVAL}

Heidegger rechazó en Ser y tiempo — $\mathrm{ST}^{1}$ (1927) — las propuestas formuladas por la metafísica creacionista relativas a un posible tránsito entre los «entes» y el denominado «ser de los entes». Se trataría de una alternativa imposible que a su modo de ver traería consigo el final de la metafísica creacionista medieval, por no decir de toda la metafísica, generando un debate que desde entonces no ha dejado de crecer. En este rechazo no sólo se incluiría el

1 Heidegger, M.; Ser y tiempo, Trotta, Madrid, 2003. 
tomismo y el escotismo, sino también las propuestas de conciliación entre ambos formuladas por Nicolás de Cusa. A este respecto Fernando Inciarte y Alejandro Llano habrían analizado el lugar que le debería corresponder a Nicolás de Cusa tras el anunciado final de dicha metafísica creacionista, en la así llamada postmodernidad. Además, habrían formulado su propuesta en 2007, en La metafísica tras el final de la metafísica - $M T F M^{2}$-, aduciendo razones estrictamente filosóficas, con independencia de las consecuencias teológicas que sin duda también se generan. Se trata de una publicación póstuma de Inciarte, recuperada y reelaborada a su vez por Llano, con una pretensión muy precisa, a saber: mostrar como sólo Dios cumpliría con las exigencias metafísicas derivadas de una interpretación realista del principio de plenitud, ya sea en la forma como habría sido enunciado por Tomás de Aquino, o incluso antes el propio Aristóteles, colocándose en las antípodas de las propuestas escotistas y hegelianas a este respecto. ${ }^{3}$

Por su parte, Johannes Hoff en El giro analógico. Repensando la modernidad con Nicolás de Cusa $-A T^{4}$-, en el 2013, ha defendido propuestas similares desde una perspectiva más teológica. Se le describe al cusano como un auténtico conciliarista que habría conseguido salvar los graves problemas filosóficos y teológicos provocados por la fundamentación escotista voluntarista de la metafísica creacionista. Especialmente los provocados por no haber tenido en cuenta el giro analógico que el tomismo habría introducido a este respecto. Sin embargo el cusano habría enmarcado la mencionada omnipotencia creacionista de los escotistas en una fundamentación analógica de la metafísica del ser al modo tomista, eludiendo así la aparición de aquellos graves problemas. En este sentido se considera al cusano como un auténtico precursor de los futuros desarrollos de la metafísica creacionista en la modernidad, tratando de dar respuesta a los nuevos retos abordados por los nuevos avances del saber respecto de una posible conciliación entre fe y razón, entre metafísica y ciencia, o entre el absoluto y lo relativo. Precisamente la tesis defendida ahora en El giro analógico es interpretar como una ventaja del cusano, lo que Heidegger acabaría considerado como un inconveniente respecto de la génesis escotista voluntarista de la metafísica creacionista, ya sea en la antigüiedad medieval o en la modernidad. En efecto, según Hoff, las propuestas del cusano permitirían complementar recíprocamente entre sí los amplios márgenes de indeterminación y las correspondientes denuncias de falta de precisión que se habrían formulado respectivamente la metafísica y la ciencia tomista y escotista, sin tener ya que concebirlas como recíprocamente incompatibles. ${ }^{5}$

2 Inciarte, Fernando; Llano, Alejandro; Metafísica tras el final de la metafísica, Cristiandad, Madrid, 2007.

3 A este respecto afirma Inciarte-Llano, resaltando la interpretación realista propuesta por el cusano del principio de plenitud: «Pues bien, el ente que fuera la totalidad de su ser sería Dios, aquel ser que es plenamente él mismo, al que no le falta nada de lo que él es o puede ser; él es — con una expresión de Nicolás de Cusa- el possest, es decir, el que es todo su poder, toda su capacidad, todo su posse. En él coinciden posibilidad y realidad. En esto van de acuerdo Tomás de Aquino y Duns Escoto, quien utiliza la expresión "tantum est, quantum potest esse". (...) Precisamente porque el ente más alto es la totalidad de su ser, y no la totalidad del ser, es inconmensurable con todos los otros entes. No puede ser la totalidad del ser, que no la hay. Pero tampoco puede ser una parte de él, porque justamente eso de lo que sería una parte, es justamente de lo que no hay (...) Es la infinidad verdadera y auténtica, no porque sea su contrario, como pretende Hegel, sino por que él es lo que es de una manera plena, sin residuos; porque es absolutamente inmanente, y no necesita en modo alguno salir de sí mismo. En esta medida es una inversión — de la Umkehrung - de la "verdadera infinitud" hegeliana» (Inciarte-Llano, MTFM, p.236).

4 Hoff, Johannes; The Analogical Turn. Rethinking Modernity with Nicholas of Cusa, William B. Eerdmans, Grand Rapids (MI), 2013.

5 A este respecto afirma Hoff: «Nicolás de Cusa desarrolló también una visión alternativa respecto del mundo que aún estaba por llegar. En contraste con las corrientes de pensamiento dominantes en su época, supo interpretar el surgimiento de la subjetividad individual y de la racionalidad científica desde una profunda lectura 
A este respecto, tanto Inciarte-Llano como Hoff, comparten las razonadas críticas formuladas por Heidegger respecto del modo escotista voluntarista y, en definitiva, nihilista, de fundamentar la metafísica creacionista por parte de la filosofía moderna, incluido especialmente Hegel y el romanticismo alemán. De hecho el cusano también habría pretendido incrementar al modo tomista los grados de libertad y las efectivas virtualidades ontológicas y científicas de la metafísica creacionista, sin introducir límites teológicos o filosóficos en sí mismos innecesarios De hecho estas ilimitadas virtualidades acabarían siendo muy importantes para el posterior desarrollo del pensamiento científico, sin tampoco tener que generar por ello los sinsentidos y paradojas que acabaría provocando el voluntarismo esencialista escotista. Al menos así habría ocurrido especialmente en la concepción de la física y de las matemáticas en Descartes y Kant, a pesar del fuerte protagonismo que en su caso se otorgó erróneamente al nominalismo de Ockham por encima del voluntarismo del propio Duns Escoto. ${ }^{6}$ En cualquier caso el cusano sólo habría exigido una condición a las distintas propuestas teológicas de la metafísica creacionista respecto del posterior desarrollo de los saberes científicos, a saber. el recurso a una fundamentación analógica a partir de un Acto de ser justificado en virtud de un principio de plenitud tomista, en vez de asignarle un fundamento escotista meramente voluntarista. En cualquier caso las diferencias entre ambas propuestas son más bien de enfoque, como ya se ha dicho: en Inciarte-Llano predomina un planteamiento filosófico del problema, en la línea aristotélico-tomista, ya señalada. Por el contrario, en Hoff, sin merma de lo anterior, se superpone un ulterior planteamiento más bien teológico, resaltando las raíces patrísticas orientales griegas asignadas en su caso al cusano. Hoff pretende así interpretar al cusano en sintonía con las propuestas formuladas por la corriente de la «ordoxia radical», iniciadas a su vez por John Milbank y Catherine Pickstock, entre otros.

\section{HOFF, 2013: LA EJEMPLARIDAD DE UN CARDENAL EN LA CORTE PAPAL CORRUPTA DE PÍO II}

En cualquier caso Johannes Hoff, en El giro analógico, ha reconstruido la dilatada vida intelectual de Nicolás de Cusa (1401-1464), destacando dos aspectos: por un lado, la intensa actividad diplomática desplegada a lo largo de su vida, sin merma, por otro lado, de la conciliación moderna operada entre tomismo y escotismo, entre la filosofía aristotélica occidental y la teología patrística oriental. De este modo habría conseguido elaborar una de las mayores síntesis teológicas del pensamiento medieval, prolongando en todo momento las propuestas de Tomás de Aquino, sin por ello dejar de divulgar sus propuestas entre la gente de la calle. A este respecto conviene destacar cuatro aspectos de su biografía, que a la larga acabarían resultando muy relevantes para la interpretación de su pensamiento, a saber: ${ }^{8}$

de la racionalidad analógica de la Edad media, haciéndolo de un modo también relevante para nosotros. Cusa revivió y transformó el camino medio de la analogía de la Edad media en una nueva forma que ahora, retrospectivamente, nos puede ofrecer nuevas orientaciones en el "ordinario absoluto caos" de la vida posmoderna»' (Hoff, AT, p. XV).

6 González, A. L.; «Nicolás de Cusa», Anuario Filosófico, vol. XXVIII, núm. 3 (1995)

7 En Ser y tiempo se formula la crítica heideggeriana a la metafísica creacionista, cuando se afirma: «El sentido del ser del ens, para la ontología medieval, queda fijado en la comprensión del ens como ens creatum. Dios, como ens infinitum, es el ens increatum. Pero ser-creado, en el sentido más amplio del ser-producido por algo, es un momento estructural esencial del concepto de ser de la antigüedad» (Heidegger, ST, p. 45).

8 Holz, Hans Heinz; Got und Welt. Problemgeschichte der Dialektik im Mittelalter. Band II. Dialektik. Problemgeschichte von der Antike bis zur Gegenwart. Band I-V, WBG -Wissenschaftliche Buchgesellschaft, Darmstadt, 2011. 
1) La difícil unión entre las dos facetas aparentemente incompatibles de su perfil biográfico: por un lado, la agitada vida de un cardenal que en todo momento habría mantenido una probada fidelidad a la Iglesia; y, por otro lado, la actividad especulativa de un intelectual que elaboró una síntesis doctrinal de gran profundidad teológica. En este contexto se destaca su inicial nombramiento como joven delegado papal (1427), así como los numerosos viajes que tuvo que hacer a París (1428), Constantinopla (1430-1432), al Concilio de de Basilea (1432-1434), al de Florencia (1437), antes de volver de nuevo a Constantinopla (1437-1438). Posteriormente, ejercería este mismo papel en Alemania, siendo nombrado obispo de Brixen (Tirol) (1450-1457), antes de retirarse definitivamente en Roma donde fallecería en 1464. Justo en Basilea habría propuesto su tesis central de la Iglesia como Cuerpo de Cristo, a la vez que también habría publicado las distintas obras más conocidas, a saber: Concordancia Catholica (1443), De Docta Ignorancia (1444), De Visione Dei (1453), De Possest (1460), así como su tetralogía sobre «De li no aliud» («El ningún otro») de 1462, junto a su corolario, «Dios no es ningún otro» (1463). Habría tratado así de resaltar la diferencia radical última existente entre el ser en su totalidad y el resto de los entes, como ahora lo exige el tránsito hacia la docta ignorancia, denotando así una fuerte dependencia de la mística germana. ${ }^{9}$

2) Su decisiva participación en las dos polémicas que acabarían teniendo una gran repercusión en la posterior crisis luterana. Por un lado, la denuncia en 1433 acerca del posible fraude de la denominada «Donación de Constantino». Se trata de un escrito espurio donde se legitimaba el traspaso al Romano Pontífice del poder religioso y temporal, cuando se trata de un supuesto imposible. Por otro lado, el descubrimiento del indudable fraude que también rodea a la propia caracterización histórica del Pseudo-Dionisio. Sus textos se atribuyeron equivocadamente a un autor griego contemporáneo de San Pablo, con el resultado de atribuirle una autoridad prácticamente indiscutida durante toda la Edad Media. Sin embargo, a pesar de todo, en la Teología Mística (1453) se reconocería la contribución de las propuestas pseudo-dionisiacas a la consolidación de una abnegada antropología neoplatónica medieval encaminada a la consecución de una efectiva divinización de la persona humana. ${ }^{10}$

3) La elaborada gestación de un original estilo intelectual. Su rasgo fundamental sería sacar la sabiduría a los callejones y plazas («sapientia foris clamat “in plateis”»), sin quedarse encerrada en los estrechos ámbitos de los claustros eclesiásticos. Especialmente así lo demostró durante su primera fase de juventud antes mencionada como legado papal ante el Sagrado Imperio Romano Germánico. Además, también habría sido entonces cuando fue nombrado cardenal en 1448, o cuando escribió los cuatro libros del Idiota de mente en $1450 .^{11}$

4) Finalmente, el final de sus días, en 1464. Se acabaría desengañando de la vida diplomática en el creciente ambiente corrupto de la corte papal de Pio II, el Piccolomini. Acabaría así optando por seguir un estilo de vida de retiro casi monástico. ${ }^{12}$

9 Hinterberger, M.; Schabel, C. (eds.); Greeks, Latins, and Intellectual History, 1204-1500, Peeters, Leuven, 2011,

10 Anónimo, atribuido a Dionysio y Escoto Eriugena; On the Ecclesiastical Hierarchy. The ThirteenthCentury Paris Textbook Edition, Harrington.L. M. (ed.); Peeters, Leuven, 2010.

11 Marenbon, John (ed); The Oxford Handbook of Medieval Philosophy, Oxford University Press, Oxford, 2012.

12 Pasnau, Robert; Dyke, Christina van (ed.); The Cambridge History of Medieval Philosophy. Vol. I-II, Cambridge University Press, Cambridge, 2014. 


\section{LA METAFÍSICA CUSANA DE LA CREACIÓN, ENTRE EL TOMISMO Y EL ESCOTISMO}

Pero por encima de estos prolegómenos biográficos, tanto Hoff como Inciarte y Llano persiguen un objetivo de mayor alcance, a saber: la reconstrucción del debate postmoderno actual antes mencionado acerca de la legitimidad de la fundamentación de la metafísica creacionista del cusano. Su origen se sitúa en las críticas formuladas por Heidegger en Ser y tiempo precisamente por no haber dado una respuesta satisfactoria al problema de la diferencia infinita intransitable que se genera entre sus respectivos extremos. En cualquier caso el cusano habría reconocido las ilimitadas posibilidades de aplicación que ahora se abren a una posible metafísica creacionista respecto del futuro desarrollo de las ciencias y de la propia cultura. De todos modos esta misma metafísica creacionista ahora se reconstruye a partir de dos tradiciones muy distintas, a saber: o bien se recurre a un principio de plenitud otorgando una primacía a la tradición filosófica aristotélico-tomista occidental; o bien se recurre a un principio analogía, que a su vez está basado en la tradición teológica patrística oriental de orientación platónica o más bien neoplatónica. ${ }^{13}$ Veámoslo.

\subsection{El uso tomista frente al escotista del principio de plenitud en Cusa}

Según Inciarte-Llano, Heidegger habría atribuido el origen de la metafísica creacionista a la interpretación preferentemente escotista del uso voluntarista del principio de plenitud. Sin embargo no habría tenido en cuenta el impacto ejercido a este respecto por una interpretación realista de dicho principio, ya fuera formulada por Aristóteles, Tomás de Aquino o por el cusano. Según dicho principio las posibilidades que se atribuyen a un ente necesariamente se realizan, si efectivamente están bien fundadas, dado que en caso contrario no se respetaría el principio de no contradicción. A este respecto el cusano habría prolongado las propuestas de Tomás de Aquino, o antes Aristóteles, justificando el efectivo cumplimiento realista de dicho principio de plenitud sólo en el caso de Dios, por ser el único que puede garantizar la efectiva realización de las posibilidades que el mismo se apropia. En este sentido el cusano no habría recurrido a los falsos atajos voluntaristas escotistas que pretenden justificar la creación entera por recurso a dicho principio, sin tampoco conseguir resolver nada. Sólo habría admitido un uso voluntarista instrumental del principio de plenitud al modo escotista para justificar una progresiva aproximación conjetural a la verdad adecuación, sin pretender otorgarle un valor definitivo. En este sentido el cusano habría otorgado a la metafísica de la causalidad y de la plenitud de Tomás de Aquino un carácter verdaderamente transcendental, situando las propuestas voluntaristas escotistas a un nivel epistemológico conjetural meramente categorial. De este modo el cusano habría conseguido desactivar numerosas paradojas y sinsentidos aparecidos en el modo voluntarista escotista de fundamentar la metafísica creacionista al pretender otorgarle un carácter verdaderamente transcendental. Pero a su vez habría admitido diversas propuestas escotistas a la hora de resolver las numerosas lagunas en el modo tomista de desarrollar las diversas ciencias particulares conjeturales a un nivel categorial. En cualquier caso el cusano habría desempeñado respecto al escotismo, un papel similar al que Aristóteles habría desempeñado respecto del platonismo. Sólo en un caso se podría

13 A este respecto afirma Heidegger, formulando una crítica a la metafísica creacionista: «Todo ente que no es Dios está necesitado de una producción, en el sentido más amplio de esta palabra, y también de conservación. [...] Todo ente que no es Dios es un ens creatum. Entre estos dos entes hay una diferencia «infinita» de ser; y sin embargo consideramos tanto al creado como al creador como entes. Empleamos, pues, el término «ser» con tal amplitud que su sentido abarca una diferencia «infinita» (Heidegger, ST, p. 114). 
defender un uso verdaderamente realista del principio de plenitud, en el caso de Dios, mientras que en los demás casos sólo se podría justificar un uso meramente instrumental o voluntarista. ${ }^{14}$

En cualquier caso el cusano habría defendido un concordismo realista tomista totalmente distinto al forzado concordismo voluntarista escotista que Heidegger le atribuía a la metafísica de la creación. En cualquier caso ahora se hace notar como la apertura realista al proceso de plenitud de la metafísica creacionista operado en Tomás de Aquino, habría sido prolongado más tarde por el cusano. Sólo así el cusano se habría podido acabar distanciado cada vez más claramente respecto de la plenitud decisionista y del voluntarismo divino donde se acabó fundamentando la metafísica creacionista de Duns Escoto. Es efecto, Nicolás de Cusa habría acabado modificando el sentido voluntarista inicial de las propuestas transcendentales escotistas, para otorgarles la plenitud categorial realista que efectivamente les corresponde. Máxime cuando se comprueba como el recurso a un principio de plenitud cusano puede resultar muy tomista, cuando se aplica a Dios, pero tiene muy poco de escotista, cuando se pretende atribuir a las criaturas. En cualquier caso Inciarte-Llano consideran que las propuestas tomistas y escotistas responden a dos modelos metafísicos absolutamente incompatibles entre sí, salvo que se proponga un uso meramente instrumental de uno de ellos. En este sentido el cusano habría simplemente prolongado las propuestas de Tomás de Aquino, tratado a su vez de evitar los numerosos malentendidos que habría acabado generando el voluntarismo epistemológico de Duns Escoto, sin colocarlo en el nivel transcendental a lo que sólo puede alcanzar un valor categorial o meramente instrumental. En cualquier caso estos mismos malentendidos se acabarían repitiendo en las interpretaciones posteriores que Heidegger habría formulado respecto de la fundamentación de la metafísica creacionista, o que más tarde también se harían presentes a lo largo de la propia postmodernidad. Se atribuyó a la metafísica creacionista una fundamentación de carácter escotista, volviendo a reincidir en los mismos malentendidos respecto de la ontología que anteriormente el primer Heidegger ya había denunciado con gran vehemencia. En su lugar, en cambio, ahora se opina que se debe volver a formular esta misma crítica en sentido contrario, para refutarlas, defendiendo la validez de una metafísica creacionista aún con más fuerza. ${ }^{15}$

\subsection{La analogía transcendente del tomismo sobre el escotismo en Cusa}

Johannes Hoff ha reconstruido, por su parte, el debate similar que el cusano habría mantenido respecto al doble uso tomista análogo o, por el contrario, escotista unívoco que se debería otorgar a la transcendencia del ser. Se atribuye así a Duns Escoto la introducción de un punto de vista unívoco acerca de la transcendencia del ente que se justificaría en virtud de la individualidad singular que cada ente debería demostrar en virtud de la haecceitas o el ser «este» o «aquel» que en cada caso se le atribuye. Sin embargo se considera que el cusano

14 A este respecto afirman Inciarte-Llano: «En definitiva, Aristóteles se ocupó con una agudeza rara vez igualada del ente en cuanto tal y de Dios, conectando además rigurosamente ambos temas. Si de algún pensador se puede decir que inició lo que desde Heidegger se considera como la excrecencia primordial que ha de ser superada y eliminada - la ontoteología - ese pensador es sin duda Aristóteles, es decir, quien ofrece más claramente una alternativa al platonismo» (Inciarte-Llano, MTFM, p. 29).

15 A este respecto afirman Inciarte-Llano: «Por el contrario, tras el final de la metafísica, es necesario hacerse cargo de las razones del escepticismo y procurar incorporarlo. Si cabe decirlo así, no se trata de vencerlo sino de sobreponerse a él. Y esta manera de proceder no es completamente ajena al pensamiento clásico, ya que a la propia Metafísica aristotélica, esta vez a lo largo de todo el libro III, se le acumulan las dificultades, porque sólo teniéndolas en cuenta, y sobreponiéndose a ellas, cabe seguir adelante» (Inciarte-Llano, MTFM, p. 17). 
habría resaltado más bien el carácter analógico o mistagógico, como ahora se prefiere decir, que se debería atribuir al carácter transcendente asignado a todos los entes. Es decir, la capacidad que pone de manifiesto cada ente de expresar una unidad previa de índole analógica muy superior, que se justifica en virtud de un principio más elevado a saber: la posibilidad de concebir la individualidad de cada ente como un don o regalo que a su vez ha recibido gratuitamente como consecuencia de su creación por parte de un ser superior fruto de su pura liberalidad, sin presuponer nada previo, partiendo simplemente de la nada. Se genera así un nuevo modo de conceptualizar la finitud de los seres singulares individuales al asignarles una transcendencia muy superior a la que podrían alcanzar por sí mismos. De hecho ya no se trataría de una simple transcendencia de carácter acumulativo o sumativo, sino que se justifica en virtud de la apropiación de perfecciones muy superiores a las suyas propias. Se genera así el milagro de contemplar a cada ente en particular como un ente que ya no se apropia de sus propiedades como si fueran «suyas», sino por haberlas recibido al modo de un regalo o don a partir de su correspondiente ser creador. Se atribuye a los entes una transcendencia muy superior con capacidad de justificar de un modo analógico la génesis de sus propiedades, sin tener que hacerlo ya de un modo simplemente unívoco. ${ }^{16}$

De este modo la metafísica creacionista del cusano, según Hoff, habría recuperado la nueva lógica analógica del ser que a su vez permite relacionar lo superior respecto de lo inferior, las perfecciones más excelsas o excedentes respecto de las más imperfectas o simplemente excedidas o dependientes. Se recupera así una visión analógica o mistagógica de los «entes», donde ya no sólo se tienen en cuenta las propiedades abstractas que se atribuyen a su respectiva individualidad de un modo unívoco. En su lugar también se podrían tener en cuenta todas aquellas otras propiedades que comparten los entes individuales con los las demás formas de entidad superior, incluida la divina, de una forma analógica o mystagógica. En este sentido la separación entre el Creador y las criaturas se diluyen, dado que en principio todas las propiedades pueden ser participadas, imitadas o copiadas por los entes inferiores, sin establecer ninguna limitación al respecto. En este sentido el cusano habría puesto de manifiesto el proceso de progresiva encarnación que puede operarse de la infinitud y de otras propiedades divinas en la finitud creada, haciendo así posible otros procesos ulteriores de encarnación aún más decisivos. En este sentido la metafísica de la creación habría sido concebida por el cusano como una preparación de la metafísica de la encarnación de la persona divina en el cuerpo de Cristo. A este respecto el cusano recupera un sentido de la teológico y cristológico de la transcendencia que tiene un origen neoplatónico claramente patrístico. ${ }^{17}$

16 A este respecto afirma Hoff: «La singularidad de las criaturas individuales nunca se puede medir o concebir de un modo analítico como si fuera una propiedad que las criaturas tuvieran, al modo de la haecceity de Duns Escoto. Sólo la imposibilidad de contabilizar el regalo de ser «uno» nos puede reportar la capacidad de descubrir en la criaturas finitas la imagen de la unidad divina [...] Solo el regalo doxológico de estimar lo inestimable puede hacernos comprender la perfección inherente a las entidades finitas. [...] Esta transcendencia es esencial para captar el modo de conocer que es propio al «fin» de nuestro deseo de conocer [...] Más aún, el milagro por el que cada criatura y cada persona, se afirma como una singularidad, no a pesar de, sino precisamente debido a que no puede apropiarse sus perfecciones como si fueran suyas. El cálculo racional acerca de la singularidad de las criaturas finitas sólo puede devaluar la singularidad del regalo» (Hoff, AT, p. 162-163).

17 A este respecto afirma Hoff: «Las abstracciones racionales siempre comparecen en una lógica comparativa entre el excedente (excendens) y lo excedido (excessum), entre lo mayor y lo menor, entre el más y el menos. En la medida que toda nuestra racionalidad está marcada por un mundo analógico, respecto de una equidad (aequalitas) donde no sólo cuentan los valores abstractos e intercambiables, sino también los valores singulares y únicos [...] Esta es la contingente singularidad de la universalidad encarnada del Dios único que media entre todas las diferencias, incluida la diferencia entre el universal y el particular» (Hoff, AT, p. 68). 


\section{EL DOBLE RECHAZO HEIDEGGERIANO DE LA ONTOTEOLOGÍA CREACIONISTA}

En cualquier caso Heidegger en Ser y tiempo rechazó este tipo de fusiones analógicas o mystagógicas entre lo infinito y lo finito, entre el Creador y la criatura, ya se legitimaran en nombre de un principio de plenitud o de la transcendencia del ser. En todas ellas se trataba de compatibilizar un doble punto de vista contrapuesto acerca de los entes, o respecto del propio ser, con una primera consecuencia inmediata: la realidad del ente y la del ser quedaba absolutamente desnaturalizada, quedando reducido a una «cosa» semejante a las demás, compartiendo un similar modo de ser, aunque se le atribuyera un grado de entidad de índole excepcional. Es más, se originaría en estos casos la denominada ontoteología que pretende justificar la naturaleza del «ser de los entes» como si se tratara de un «ente» o «cosa» igual a los demás, aunque se le asignaran unas propiedades excepcionales. Hasta el punto de no poder reconocerse la infinita distancia existente entre ambos extremos de la relación, ni tampoco poderse ya concebir como el fundamento de todo ente, dado que se trataría más bien de una «cosa» similar a las demás. ${ }^{18}$

\subsection{EI diferente uso voluntarista y realista del principio de plenitud}

Por su parte, Inciarte-Llano habrían rechazado en 2007 estas propuestas heideggerianas. Se hace notar la persistencia en su caso del incorrecto uso que el mismo había denunciado del principio de plenitud por parte de Duns Escoto, sin proponer tampoco ninguna corrección pertinente. Según Inciarte y Llano, las iniciales denuncias heideggerianas formuladas respecto de Duns Escoto se habrían acabado volviendo en contra suya, sin conseguir tampoco los resultados esperados. Especialmente cuando se comprobó un segundo acercamiento heideggeriano al uso voluntarista escotista del principio de plenitud, que era claramente contrario a su inicial rechazo al respecto. En este contexto Inciarte-Llano denunciaron el paradójico giro voluntarista que el último Heidegger y después el pos-estructuralismo francés habría acabado haciendo del mencionado principio de plenitud a partir de Duns Escoto, sin tampoco quererlo reconocer. De hecho el primer Heidegger rechazó en Ser y tiempo la relación simplemente aditiva que de un modo voluntarista los escotistas establecen entre cada «ente» en particular y el respectivo «ser de los entes», que a su vez los engloba a todos por igual. De igual forma que el primer Heidegger también habría rechazado la simultánea relación de intencionalidad que, según los escotistas, los conceptos universales mantienen a su vez de un modo aditivo voluntarista respecto de cada uno de los casos individuales a los que en cada caso se remiten, con la única pretensión de poderlos englobar así dentro de un mismo concepto. Al menos así habría sucedido con los conceptos más universales, como ahora ocurre con la noción genérica de «ente» o de «substancia». En efecto, en estos supuestos la voluntad puede añadir un número ilimitado de casos individuales que de este modo podrían quedar englobados bajo un mismo concepto, sin poder ya poner un término a este tipo de procesos. ${ }^{19}$

18 A este respecto afirma Heidegger: «La distinción tan manifiestamente obvia entre el ser del Dasein existente y el ser de los entes que no son el Dasein (el ser-ahí, por ejemplo) es tan sólo el punto de partida de la problemática ontológica, y no algo en lo que la filosofía pudiera encontrar reposo. Que la ontología antigua opera con «conceptos de cosa» y que se corre el riesgo de «cosificar la conciencia» es algo sabido desde hace tiempo» (Heidegger, ST, p. 448).

19 A este respecto afirman Inciarte-Llano: «La libertad de albedrío o de decisión tiene que ver más bien con el uso que hacemos de la libertad fundamental, que es la única libertad necesaria para la formación de conceptos. [...] De ahí que Duns Escoto llegue a mantener que la única facultad no natural, sino exclusivamente racional, es precisamente la voluntad, porque a ella se aplica el lema aristotélico "Natura ad unum, ratio ad opposita". Mientras que la propia razón es, paradójicamente, más natural que racional. Hasta el punto de que, 
En cualquier caso el segundo Heidegger habría seguido proponiendo una interpretación voluntarista de dicho principio de plenitud similar a la de Duns Escoto, a pesar de sus críticas iniciales al respecto. De ahí que, finalmente, se acabara distanciando cada vez mas del uso realista que habrían propuesto Tomás de Aquino o Nicolás de Cusa de dicho principio. De hecho, seguir una interpretación u otra, dependería exclusivamente de que los individuos singulares aceptasen o no la referencia a uno de estos dos posibles horizontes interpretativos, a saber: o bien la referencia a un ser global o a unos conceptos universales simplemente acumulativos de un modo voluntarista; o bien remitirse a Acto de ser puro que se afirma como un fundamento realista de la existencia de los demás seres, estableciendo una clara separación entre ellos. Con la circunstancia añadida de que al asignar un fundamento real a este tipo de horizonte interpretativo, también se podría garantizar una adecuada apropiación de su específico modo de ser, ya sea respecto del «ser de los entes» o de los correspondientes conceptos universales, sin quedar reducida a una simple apropiación voluntarista sobreañadida o superpuesta venida de fuera. Se localiza así un fundamento proporcionado a este tipo de apropiaciones metafísicas y epistémicas, ya sea respecto de los entes o de los conceptos. Sin embargo el último Heidegger rechazaría este tipo de apropiaciones a su modo de ver totalmente desmedidas, volviendo a defender un uso simplemente voluntarista de este principio al modo escotista. Especialmente cuando el último Heidegger denuncie la distancia intransitable que a su modo de ver en todos estos procesos se establece entre ambos extremos de dicha correlación. ${ }^{20}$

\subsection{La coincidencia de los opuestos en la metafísica creacionista de Cusa}

Johannes Hoff también ha denunciado, por su parte, las consecuencias tan negativas que ha generado en la posmodernidad el rechazo por parte de Heidegger a una metafísica creacionista. Especialmente cuando se comparan las reacciones apocalípticas tan distintas que se originaron en el cusano y en Derrida a este respecto. En efecto, la postmodernidad interpretará el futuro que aún está por llegar como una vuelta a la facticidad voluntarista que, según Duns Escoto, define el modo de ser de los individuos singulares, sin poder ya garantizar la mediación de un lazo de unión transcendente entre todos ellos. O mejor dicho, correlacionándolos mediante un simple «juego de lenguajes», que exige el previo reconocimiento de la «desnudez» y de la «pobreza» de la condición humana, con la única promesa de poder establecer un modo todavía más anárquico y asistemático de proceder. En cualquier caso la metafísica creacionista habría sido un caso más donde la humanidad se habría dejado llevar por la estéril ilusión de encontrarnos ante un mundo entorno que ha sido creado a la medida de nuestras posibilidades. Sin embargo para la posmodernidad lo único que cabe esperar es la referencia a un «ser en cada caso completamente distinto», siendo nuestra voluntad la única responsable de la orientación y de la significación otorgada en cada caso. ${ }^{21}$

para Duns Escoto, la voluntad es un agente superior a la razón, a la que controla. Sin llegar al voluntarismo que este planteamiento implica, es preciso reconocer que hay en él algo de cierto. Porque, efectivamente, la razón se halla más entrañada en la naturaleza que la voluntad» (Inciarte-Llano, MTFM, p. 153).

20 Afirma Inciarte-Llano: «El concepto es producto de la libertad en cuanto que este concepto no tendría que haberse formado necesariamente; que, en lugar de él, se podría haber formado otro; y que, en esa medida, en su formación no han tenido parte factores que — como en la representación o en el juicio_- no fueran objetivos: ninguna causa natural ha sido su condición suficiente. Las representaciones están sometidas a la causalidad natural, los conceptos no [...] Según mantuvo Duns Escoto, solo la voluntad — no la inteligencia — puede actuar contra la captación (del universal). En lo cual hay, seguramente, mucho de verdadero» (Inciarte-Llano, MTFM, p. 158-159).

21 A este respecto afirma Hoff: «Esta desconcertante actitud apocalíptica pone en conexión a los escritos de Derrida con aquellos de Nicolás de Cusa, y Derrida fue perfectamente consciente de esta conexión. [...] Sin 
De todos modos, según Hoff, el cusano nunca habría sacado tales consecuencias de dichos planteamientos escotistas. En su opinión, la individualidad y la singularidad de los entes simplemente manifiesta la riqueza y variedad a las que puede dar lugar el primer principio creador, no en virtud de las cosas mismas, sino en virtud del autor que las ha creado con absoluta liberalidad a partir de la nada. Se produce así la ahora denominada coincidencia de los opuestos en Dios. De hecho, si la mirada fuera capaz de seguir todos los movimientos de una figura visible, tendría que reconocer la multiplicidad de estados por los que podría pasar, sin por ello lesionar en ningún momento el llamado principio de contradicción. Pero a la vez tendría que reconocer su procedencia a partir de la infinita sabiduría y omnipotencia divina, que a su vez ha generado toda aquella infinitud de opuestos. De hecho la semejanza entre el Creador y la criatura se estrecha, en vez de acrecentarse, como ocurría antes. ${ }^{22}$

\section{EL VOLUNTARISMO Y LA UNIVOCIDAD ESCOTISTA EN LA CIENCIA MODERNA}

El primer Heidegger también habría hecho extensiva a la metafísica creacionista medieval la ausencia de una auténtica reflexión acerca de los conceptos fundamentales de la ciencia moderna. Máxime cuando se habría fomentado un mal uso voluntarista o simplemente creacionista del específico hilo conductor que en cada caso hubiera permitido relacionarlos con su correspondiente fundamento, ya fuera por recurso a un uso realista del principio de plenitud o a la correspondiente noción analógica de transcendencia. Sin embargo la ciencia moderna habría seguido un modelo escotista de fundamentación de sus conceptos básicos fundamentales. Los habría justificado en virtud de meras decisiones, o por simple acumulación de experiencias, sin llevar a cabo una previa reflexión sobre el

embargo el "juego de lenguajes" de ambos presenta una profunda disparidad. La más significativa disparidad se refiere a la actitud favorable de Derrida respecto de la ontología unívoca de la tradición escotista recibida a través de Martín Heidegger. Los profetas apocalípticos de la postmodernidad, desde Lévinas hasta Derrida discípulo de Jean-Luc Marion, asumen y presumen de que el encuentro con la desnudez y la pobreza de la condición humana sólo puede tener sentido en el modo anárquico de concebir un "ser totalmente distinto", esto es, concibiéndolo como un evento que transciende la facticidad de nuestro ser en el mundo en la medida que le podemos asignar un significado y una dirección. En la medida que se admiten las herramientas escotistas de las ontologías y epistemologías modernas, esta sospecha es consecuente, aunque Duns Escoto no habría compartido el nihilismo que el mismo habría fomentado» (Hoff, AT, p. 192).

22 A este respecto afirma Hoff: «Todo esto nos lleva al concepto clave de la sabiduría acerca de lo desconocido. Como ahora ocurre con la "coincidencia de los opuestos" (coincidencia oppositorum). Puede resultar sorprendente que la mirada pueda seguir todos los movimientos individuales de una figura visible [...], aunque pueda parecer imposible. [...] Pero fenómenos como este resultan aún consistentes con la ley de (no) contradicción. Fenómenos extraordinarios pueden parecer imposibles, pero no resultan imposibles por necesidad. Por el contrario, el hecho que la mirada, mientras mira a cada individual como si no le concerniera a nadie más. En cambio que se pueda mover en direcciones opuestas constituye una rigurosa "imposibilidad", que va en contra de la ley de contradicción. Como Cusa señala, esta mirada en todas las direcciones puede tratarse de un simple ejemplo de una "imposibilidad que pueda coincidir con la necesidad" (imposibilitas coincidit cum necesitate, c9 n 37, 7). Este último punto es fundamental para el concepto cusano de Dios. Los principios de la razón humana requieren una distinción entre determinaciones opuestas.[...] El concepto de Dios es inconcebible por definición con las distinciones mediante definiciones dialécticas o analíticas. En esto consiste, de un modo simplificado, la paradoja de la coincidencia de los opuestos (coincidencia oppositorum). Nosotros no podemos concebir lo que la palabra "Dios" significa, porque resulta de imposible definición cada una de las palabras que se refieren a la infinita realidad. Sin embargo, el significado de la palabra "Dios" no resulta inconcebible. La infinidad de Dios no es una obscuridad tenebrosa en la que todo se haga indistinguible» (Hoff. AT, p. 29-30). 
peculiar ámbito óntico donde cada una se sitúa, como también sucederá en la segunda época de Heidegger. ${ }^{23}$

\subsection{El voluntarismo cosificado de la ciencia moderna}

A este respecto Inciarte-Llano comparten en gran parte la crítica que Heidegger formula a la ciencia moderna. Sin embargo consideran injustificado generalizar esta denuncia a todas las formas de filosofía antigua, incluido Tomás de Aquino o Cusa, cuando el principal responsable de esta situación habría sido la filosofía escotista. En su opinión, la justificación escotista del saber por recurso a un ser omnipotente, sólo sería consecuencia de un uso voluntarista arbitrario que en su caso se habría hecho del principio de plenitud. No se habría advertido que el caso del Creador es muy distinto al de las criaturas. Por eso Duns Escoto terminaría concibiendo al Ser supremo como un simple resultado de su poder ilimitado de superponer aditivamente distintas «cosas», sin apreciar que se estaba fomentando un simple uso voluntarista del principio de plenitud respecto de dos casos específicamente distintos. Pero igualmente, también se habría concebido la intencionalidad del concepto de «ente» como una mera función sustitutiva vicaria acumulativa, siempre abierta a un proceso de ampliación o de simple reagrupación arbitraria aún mayor, sin necesidad de remitirse al correspondiente acto de ser de cada uno de los entes. De este modo, tanto el Ser supremo como las criaturas, acabarían siendo resultado de un uso meramente voluntarista del principio de plenitud. En ambos casos se generan simples relaciones acumulativas entre «cosas», sin necesidad de hacer referencia al correspondiente acto de ser de los respectivos sujetos individuales afectados. En cualquier caso Duns Escoto asignaría, tanto a los entes como al alma o a Dios, un mero «esse diminutum» o minimalista, que a su vez da lugar a una simple acumulación de otras cosas materiales y concretas. Por eso no sería necesario recurrir a mediaciones especiales de carácter existencial o conceptual que a su vez permitieran ordenar y jerarquizar los correspondientes procesos de ampliación o reagrupación ahora generados por la noción de «ente». O mejor dicho, se concebirían como ámbitos de realidad que se superponen en virtud de la plena superioridad voluntarista que a este respecto Dios ejerce sobre los entes, o que la inteligencia ejerce a su vez sobre la experiencia. ${ }^{24}$

En cualquier caso Duns Escoto se habría visto obligado a proyectar sobre la inteligencia discursiva un modelo «cosificado» similar a las relaciones que en su caso se establecen entre la omnipotencia y omnisciencia del entendimiento divino y la haecceitas de cada ente en particular; o las relaciones similares que se deben establecer entre los conceptos universales y cada individuo singular concreto. Se habría generado así una mera relación intencional entre una plenitud de cosas infinitas respecto de la fragmentación de una multiplicidad de haecceitas individuales meramente finitas; o entre una agrupación universal de cosas respecto de los

23 A este respecto afirma Heidegger: «Los conceptos fundamentales [...] reciben, pues, su genuina justificación y "fundamentación" únicamente [...] en virtud de la función que la configuración de este ente desempeña en la constitución fundamental de su ser.[...] Pero semejante cuestionamiento [...] necesita de un hilo conductor. El preguntar ontológico es ciertamente más originario que el preguntar óntico de las ciencias positivas. Pero el mismo sería ingenuo y opaco si sus investigaciones acerca del ser del ente dejaran de examinar el sentido del ser en general» (Heidegger, ST, pp. 31-32). .

24 A este respecto afirman Inciarte-Llano: «A Dios no se le puede representar, porque no es un qué, no es esto o aquello, no es cosa alguna; sólo se le puede hacer presente, que es lo que hace el mundo, tomado no como mundo, como esfera de nuestra afirmación, de nuestra actividad cotidiana — científica, artística, o políticasino como creación. Tan pronto como al mundo se le toma, no como mundo, sino (metafísicamente) como creación, se hace transparente a Dios, deja traslucir su presencia sin necesidad de parecerse a él; es similitudo Dei, aunque no sea similis Deo» (Inciarte-Llano, MTFM, p. 356). 
correspondientes singulares en sí mimos particulares. Inciarte-Llano denuncian así la introducción por parte de Duns Escoto de una innecesaria naturalización del entendimiento divino y humano. De hecho la propia omnisciencia divina o los propios procesos de abstracción se concebirían como una mera función pasiva de reproducción mimética de formas naturales finitas preexistentes. Se habría seguido concibiendo las relaciones que Dios o el alma mantienen con los «entes» al modo de una simple relación entre «cosa» y «cosa». En cualquier caso Inciarte y Llano ya no consideran suficiente el recurso a una plenitud entitativa de carácter voluntarista, ni la reagrupación universal en sí misma decisionista, como habría ocurrido en Duns Escoto. En este sentido opinan la separación entre el Creador y la criatura debe incrementarse, en vez de disminuirse, como ahora es el caso. ${ }^{25}$

\subsection{La transcendencia unívoca cusana de la futura Era humanista}

Por su parte, Hoff también comparte la crítica de Heidegger a la ciencia moderna. Sin embargo también discrepa respecto de la atribución de esta laguna a la metafísica creacionista del pensamiento antiguo, y en particular al cusano, cuando a su modo de ver su origen hay que seguir situando esta desviación en Duns Escoto. En su opinión, el universo digital de Descartes y Leibniz perpetuaron el uso unívoco que Duns Escoto propuso de la noción de transcendencia, como una simple suma o agregación representacionista de individuos singulares, sin introducir los correctivos necesarios al respecto. De hecho deberían haber situado a los universales y a los singulares en dos niveles de consideración muy distinta. Sólo así se habría podido dar entrada a otro tipo de mediaciones contingentes, ya sea en el ámbito del ser o de los conceptos. En cualquier caso Cusa no habría estado dominado por esta obsesión moderna de tipo representacionista. Por eso había admitido sin problemas la referencia a entidades o a conceptos que se sitúan más allá de la referencia a simples individuos singulares. Especialmente la referencia que todo individuo singular hace a Dios a la hora de glorificar la magnificencia de la creación, o para simplemente expresar su pertenencia a un mundo natural. En estos casos resulta claramente insuficiente el recurso a un mero pensamiento abstracto y a sus correspondientes oposiciones y comparaciones, donde ya este tipo de horizontes de comprensión ya no comparecen. Sin embargo sería un error atribuir a este tipo de comprensión analógica un carácter religioso o simplemente voluntarista. En su lugar más bien se les debe otorgar un carácter verdaderamente científico ya que permiten circunscribir el ámbito óntico respecto del que se está ocupando un determinado saber, con independencia del tipo de transcendencia natural, cultural o teológica que en cada caso se le asigne. ${ }^{26}$

25 Inciarte, F.; Forma formarum : Strukturmomente der thomistischen Seinslehre im Rückgriff auf Aristoteles, Alber, Freiburg, 1970.

26 A este respecto afirma Hoff: «El universo digital de Descartes y Leibniz no deja lugar para este tipo de mediaciones contingentes, debido a que no reconoce la separación [...] que el universal evita respecto del singular y único. Cusa no necesita negar dicha separación, dado que tampoco subscribe la obsesión moderna respecto de la seguridad representacionista. Por eso que el considere nuestro deseo natural de ver a Dios como algo más que una exigencia religiosa. La gloria de Dios resulta ser una cuestión con significado científico. [...] La visión de Dios resulta a la vez universal y particular (est Universalis pariter et partcularis, c 9). Universal ya que no disponemos de un criterio que nos permita generalizar una abstracción hasta lo particular y único. Consecuentemente el criterio absoluto de nuestra investigación acerca de la verdad sólo puede ser tentativamente aproximativo en el lenguaje analógico de la oración y alabanza que une lo universal con lo particular[...] El espíritu de las oposiciones y comparaciones relativas debe ser vencido si nosotros pretendemos que los principios universales puedan relacionarse con cualquier cosa: no es posible desarrollar una visión universal del mundo al nivel de las simples abstracciones o de un simple cálculo proporcional matemático» (Hoff, AT, p. 69). 
En cusano habría anticipado así la localización de unos absolutos naturales, ónticos o simplemente teológicos, que serían muy similares a los que posteriormente serían afirmados de un modo incondicionado por los primeros románticos, o por los propios iniciadores de la física contemporánea. De este modo habría logrado conciliar la simplicidad que ahora se asigna a este tipo de principios con el carácter simultáneamente análogo o mystagógico que se les atribuye a la complejidad estructural que manifiestan determinados individuos singulares. Sin embargo ahora también se hace notar la referencia a determinados presupuestos teológicos que permitieron al cusano concebir la creación como una manifestación de las excelencias insondables de su Creador. En cualquier caso no se habría dejado llevar por la sospecha melacólica y necrofílica de atribuir al mundo un posible fracaso o un destino efímero, como sucedió en el romanticismo. En su opinión, hay razones teológicas bien fundadas que permiten establecer desde un punto de vista místico una unidad indivisible e inseparable entre el mundo y Dios, a pesar del modo de ser tan diferente que se les asigna. ${ }^{27}$

\section{LA INSERCIÓN CUSANA ENTRE CIENCIA Y METAFÍSICA}

De todos modos el primer Heidegger retrotrajo los problemas originados por la ciencia moderna a un momento previo, a saber: las deficiencias que ya estaban presentes en el punto de partida de la metafísica creacionista, ya fuera medieval o moderna. Si de hecho la ciencia moderna no terminó de localizar el rango óntico donde se situaban sus respectivas investigaciones, se debe, según Heidegger, a que tampoco la metafísica clásica se habría propuesto llevar a cabo este tipo de análisis. De hecho ni habría llevado a cabo un análisis del término «ser» tomado en un sentido transcendental en toda su amplitud, ni tampoco habría procedido a un análisis categorial del diferente rango óntico que le corresponde a cada forma de saber. De todos modos ahora se hace notar como Nicolás de Cusa habría advertido la necesidad de insertar el respectivo plano categorial en el correspondiente plano transcendental, ya sea por el recurso a un principio de plenitud o de analogía. En cualquier caso la exigencia de separar el Creador respecto de la criatura, no debe impedir su recíproco acercamiento, y viceversa. ${ }^{28}$

27 A este respecto afirma Hoff: «El punto de vista mystagógico de Cusa pone su acento en la simplicidad de lo absoluto y de lo incondicionado, como de algún modo también ocurre en Fichte y en la filosofía del primer romanticismo. Sin embargo este enfoque no genera una actitud de sospecha melancólica y de necrofilia respecto de la imperfecta belleza del mundo. Indudablemente, ahora (el cusano) pretende hacer compatible la belleza del mundo con la plenitud de su creador mediante un procedimiento que conduce al paradigma de concebirnos como hijas e hijos (filiatio) de Dios. Para usar la terminología del dogma revelado definido en el Concilio de Calcedonia (451): aunque desde un punto de vista místico el espacio de nuestro mundo es indivisible e inseparable de su principio invisible, también es inalterable en términos del carácter compuesto (y, por tanto, alterable) de su propio modo de ser y de querer, sin poderlos ya confundir con la pureza inalterable del divino modo de ser (modus essendi)» (Hoff, AT, p. 118).

28 A este respecto afirma Heidegger: «Se trata de un problema que dio mucho que hacer a la filosofía medieval: el problema del modo como la significación (transcendental) del ser afecta (de un modo categorial) a cada uno de los entes de que se habla. En los enunciados "Dios es" y "el mundo es" afirmamos el ser. Pero la palabra "es" no puede decirse de ambos antes en el mismo sentido (univoce), puesto que entre ambos hay una diferencia infinita justamente respecto del ser. [...] La escolástica concibe el sentido positivo de la significación del término ser como una significación "análoga" a diferencia de la unívoca y de la simple significación del nombre. [...] Sin embargo, ni la ontología medieval ni la antigua cuestionaron lo que significa el ser mismo. [...] $\mathrm{Y}$ el sentido ha quedado sin aclarar porque se lo considera una cuestión obvia [...] El ser mismo no nos "afecta", y por eso mismo no puede ser percibido» (Heidegger, ST, pp. 114-115). 


\subsection{El tránsito cusano desde las categorías lógicas hasta la trancendencia metafísica}

Inciarte-Llano han puesto de manifiesto en 2007 la concordancia que el cusano habría postulado entre el plano categorial lógico y transcendental metafísico donde en principio se sitúan los entes. A este respecto primero se habría justificado la diferencia existente entre ambos planos en virtud del distinto uso que en cada caso se puede hacer del principio de plenitud. Sin embargo, en un segundo momento, se sitúa a Cusa en la tradición tomista y, en definitiva aristotélica, que acabaría proponiendo una interpretación analógica del mencionado principio de plenitud. ${ }^{29}$ Se establece así una clara articulación entre los dos posibles modos de aplicar dicho principio de plenitud: por un lado, la aplicación realista del principio de plenitud en un plano transcendental que se aplicaría especialmente a Dios y a sus atributos, pero que a su vez debería permitir fundamentar el modo de ser del resto de los entes. Se comprueba así como todos los entes se remiten de un modo analógico a un Acto de ser único, que ahora se afirma como la plenitud de su ser; y, por otro lado, su posterior aplicación jerarquizada al resto de los conceptos, formas y naturalezas que ahora configuran el plano simplemente categorial y que se pueden llegar a conocer mediante una aplicación voluntarista de dicho principio de plenitud. Sólo así el principio de plenitud se podría remitir alternativamente de un modo transcendental y categorial a Dios y a los respectivos individuos singulares, a fin de fundamentar el respectivo grado de entidad que en cada caso les corresponde. Además, se podría postular una doble extrapolación diferenciada analógica o simplemente estricta del principio de plenitud a tres nociones metafísicas fundamentales, como son la noción de ser, de lo infinito o de lo perfecto. Todo dependerá de que se aplique a supuestos en sí mismos relativos donde se fomenta una aplicación categorial o simplemente voluntarista de tales principios; o bien que se aplique a supuestos absolutos a los que les corresponde una efectiva «plenitud de su ser» donde se tendrá que fomentar una aplicación alternativamente transcendental y realista de tales principios. ${ }^{30}$

Inciarte-Llano fomentan así un uso gradual de dicho principio de plenitud en razón del acto de ser que en cada caso le corresponde a cada ente. Se trata, por tanto, de una plenitud ontológica que propiamente sólo se asigna al Ser supremo y, por extensión, a la infinitud del intelecto divino. Sólo después, en un segundo momento, también se aplicaría de un modo subsidiario a las criaturas. En cualquier caso se atribuye al Ser supremo un Acto puro al que se le atribuye una efectiva plenitud de «su ser», aunque de un modo analógico también se podría atribuir al resto de los seres. En cualquier caso no se debe asignar al resto de los «seres» una plenitud de ser mediante sucesivas adiciones voluntaristas de los correspondientes «esse diminutum» o minimalista, como pretendía Duns Escoto. Se configurarían así un tipo de totalidades o agrupaciones meramente voluntaristas, que serian muy distintas a la plenitud de «su» ser que se atribuye al Ser supremo y, subordinadamente, al resto de los entes. En cualquier caso al resto de los seres no se les debe atribuir una totalidad de «ser», que ni puede ser total ni es plena, como corresponde a las simples criaturas, que sólo poseen «su ser» de un modo analógico. ${ }^{31}$

29 Kosman, A.; The Activity of Being. An Essay on Aristotle's Ontology, Harvard University Press, Cambridge (MA), 2013.

30 Llano, A.; «Aquinas and the Principle of Plenitude», en D. Gallagher (ed.); Aquinas and his Legacy, CUA - The Catholic University of America, Washington, 1993.

31 A este respecto afirman Inciarte-Llano, resaltando como el principio de plenitud sólo se aplica verdaderamente a Dios: «Según acabamos de ver, lo que es la totalidad de su ser no es una parte del ser. Porque entonces también cabría pensar en convertir la proposición en afirmativa y tendría sentido metafísico decir: esto es la totalidad del ser. Pero lo cierto es que, según se ha advertido ya, tal afirmación no es mantiene metafísicamente. 
De este modo Inciarte-Llano atribuyen al Acto puro una plena posesión de «su ser» (el «posset», en terminología de Nicolás de Cusa). ${ }^{32}$ Pero a su vez el acto de ser divino debería ser capaz de comunicar de una forma limitada su peculiar modo de apropiarse «su propio ser» al resto de las criaturas materiales. De hecho «uno» es el Creador y los «otros» entes habrían sido creados a partir de la nada, siendo de suyo simplemente nada. Se vuelve a resaltar la separación entre el Creador y la criatura. Pero a la vez se logra evitar que la totalidad de los entes se sigan concibiendo de un modo simplemente unívoco, al modo de un simple «entemasa», como si se tratara de una simple cosa o suma de cosas o de haecceitas individuales con su correspondiente «esse diminutum». En su lugar el cusano habría pretendido establecer una gradación de menos a más entre sus respectivos modos realistas de aplicación de un principio de plenitud respecto de la apropiación del correspondiente modo de ser, ya sea en el caso de Dios o de la criatura. Se genera así una jerarquización entre dos extremos: por un lado, las criaturas a las que se les atribuye un «ser» que las sobrepasa, por ser en sí mismas limitadas, por no decir «nada», aunque a su vez tienen su propio ser; y, por otro lado, el Creador, que es el Acto de ser puro, que se apropia plenamente de «su» ser infinito que sólo a él le pertenece. De todos modos la voluntad siempre puede producir alternativamente una inadecuada absolutización de una naturaleza, atribuyendo erróneamente una plenitud de «su» ser a un conjunto de entes en sí mismos contingentes y finitos, como si verdaderamente pudieran apropiarse de una noción de «ser» que les sobrepasa completamente. En cualquier caso la posesión de su ser, según el cusano, sólo se puede atribuir de un modo estricto al Acto puro o Ser supremo. De ahí que ahora Dios se conciba como el punto más alto de la reflexión especulativa o metafísica, sin poderlo ya reducir en ningún caso a una mera criatura. ${ }^{33}$

\subsection{El doble uso analógico e icónico de la metafísica cusana en una Era humanista}

Por su parte, Hoff también sigue una estrategia similar a la propuesta por Inciarte-Llano, aunque la formule desde presupuestos muy diferentes. En su opinión, el cusano también habría tratado de establecer una estricta separación entre aquel plano categorial lógico y este otro transcendental metafísico. Se trataría de dos ámbitos que naturalmente se encuentran unidos, pero que habrían vuelto a quedar separados a consecuencia de la crisis de los universales. Especialmente cuando la geometría de Alberti habría tratado de justificar un posible tránsito desde el espacio finito hasta el espacio proyectivo infinito, con el único fin de naturalizar este tipo de procesos. Sin embargo el cusano comprueba como las propuestas de Tomás de Aquino, Ockham y Duns Escoto, habrían incrementado la diferencia última que ahora se establece entre ambos planos. En cualquier caso la naturalización del espacio infinito postulada por Alberti ya no sería posible, por cuando siempre nos encontramos con espacios proyectivos en sí mismos finitos. Se habría originado así un problema que tampoco la modernidad o la propia postmodernidad habrían terminado de resolver. A este respecto la mayor virtualidad de las propuestas del cusano habrían consistido en mostrar el doble uso analógico e icónico del

Pues, con independencia de qué cosas hay o no, no existe algo así como el ser; sino que en cada caso el ser es esto o aquello, como siendo plenamente su ser o no. Cada cosa es solamente ella misma en cada caso. Esta es la diferencia fundamental, mejor la distinción fundamental. [...] Presupuesta esta diferencia fundamental, se pueden dar intersecciones o solapamientos, interferencias, coincidencias, intercambios, de modo que una casa sea parte de otra» (Inciarte-Llano, MTFM, p. 242).

32 González, A. L.; "Nicolás de Cusa: De Possest», Servicio de Publicaciones de la Universidad de Navarra, 1992. (2 a ed. corr. 1998).

33 A este respecto afirman Inciarte-Llano: «Cada uno es solamente "su ser" no significa: cada uno es su ser, es ya su ser, es plenamente su ser. Significa más bien: nada va más allá de su ser, pero nada plenifica su propio ser» (Inciarte-Llano, MTFM, p. 242). 
principio de plenitud tomista a fin de mostrar como las nociones de unidad, infinito y otras semejantes, tienen una doble aplicación: o bien hacen una referencia icónica sobreentendida al único que las posee verdaderamente por pertenecerle esencialmente, a saber, el Ser supremo. O bien se remiten a los demás entes, incluidos los propios individuos singulares, a los que también se atribuyen estas mismas propiedades de un modo secundario, o simplemente analógico, en cuanto de algún modo participan de un modo limitado del modo de ser de la divinidad. Para justificar estas conclusiones se dan tres pasos: ${ }^{34}$

a) La necesidad de reformular las relaciones de contraposición y de complementariedad existentes entre los opuestos. Al menos así ocurre especialmente con las relaciones entre razón y fe, o entre metafísica y ciencia, o entre la geometría plana y la geometría proyectiva, sabiendo que se trata de un problema abierto que, como habría mostrado Duns Escoto, siempre admitirá la posibilidad que surjan nuevos retos de contraposición aún más indisociables. Máxime cuando se pretenden seguir defendiendo las exigencias de autonomía heurística decisionista reivindicadas de un modo infinitista por cada ciencia particular en la futura Era humanista. ${ }^{35}$

b) La necesidad de justificar los procesos de divergencia y convergencia recíproca que ahora genera el recurso a un primer giro analógico, como el ahora descrito. Especialmente cuando el centro focal de este proceso en sí mismo infinitista se proyecta de un modo decisionista sobre una multiplicidad de representaciones en sí mismas finitas y contingentes al modo escotista. Con la dificultad añadida de tener que seguir manteniendo, además, un absoluto respeto a la separación entre dos actitudes opuestas: por un lado, las nuevas exigencias de autonomía decisionista reivindicadas de un modo infinitista por las pretensiones escotistas y nominalistas de iniciar una nueva cultura humanista estrictamente convencional; y, por otro lado, la imposibilidad de poder dar un salto en el vacío de carácter ultrarrealista en estas condiciones, a fin de permitir garantizar la adquisición de una plena verdad adecuación al modo tomista. ${ }^{36}$

c) Sin embargo, en un tercer momento, se hace notar como el recurso a una doble noción de analogía y de iconología o simbología debería permitir salvar la infinita distancia que Duns Escoto estableció de un modo decisionista entre aquellos dos puntos de vista cada vez más enfrentados. Máxime cuando resulta cada vez más difícil elevarse hasta un nivel previo de solidaridad social en sí misma infinitista a partir exclusivamente de unos sentimientos egoístas en sí mismos finitistas que deliberadamente se colocan de un modo arbitrario en el otro extremo de la relación. A este respecto siempre habría que estar abiertos a formas de configuración del cuerpo social que, como mostró Duns Escoto, podrían ser aún más disolventes. Sin embargo en estos casos siempre sería posible remitirse de un modo icónico o simbólico a un modelo ideal que a su vez permitiera justificar la apropiación de la multiplicidad de sentimientos de los diferentes miembros de la humanidad que a su vez configuran el propio cuerpo Cristo, por mediación de la Iglesia. ${ }^{37}$

34 Taylor, Richard, Twetten, David, Wreen, Michel (eds.); Tolle Lege. Essays on Augustine on Medieval Philosophy in Honor of Roland J. Teske, SJ.; Marquette University Press, Marquette, 2011.

35 Oppenraay, Aafke M. I.; Fontaine, Resianne (eds.); The Letter before the Spirit: The Importance of Text Editions for the Study of the Reception of Aristotle, Brill, Leiden, 2012

36 Totaro, Pina; Valente, Luisa (eds.); Sphera. Forma, imagine e metáfora, tra medioevo ed etá moderna. Leo S. Olschki, Firenze, 2012.

37 Averroes Latinus; Commentum Medium Super Libro Predicamentorum Aristotelis. Translatio Wilhelmo de Luna Adscripta. Averroes Opera. Series B, XI, Hissette, R.; Bertolacci, A.; Bataillon, L. J. (eds.); Peeters, Lovanii, 2010. 


\section{LA COMPATIBILIDAD ENTRE EL PRINCIPIO DE PLENITUD Y LA ANALOGÍA DEL ENTE EN CUSA}

Finalmente, el primer Heidegger también hizo notar como la metafísica creacionista tiene un presupuesto previo que ni Descartes ni la filosofía moderna tampoco se lo habrían planteado, a saber: analizar las diferencias últimas que en cualquier caso se deben establecer entre el Ser supremo y el resto de los entes o entre el Creador y las criaturas. Se trataría además de un problema que, según Heidegger, la filosofía moderna se habría quedado aún más rezagada en su modo de fundamentar la ontología respecto del modo como lo habría abordado la metafísica creacionista medieval. Al menos la metafísica creacionista lo habría abordado de un modo meramente quiditativo a nivel de esencias, sin advertir que se trataba de un problema a un nivel específicamente transcendental. De todos modos ahora se comprueba como a lo largo de la filosofía medieval, ya sea en el caso del tomismo, de Duns Escoto o del cusano, se habrían hecho propuestas muy precisas a este respecto, con independencia de que Heidegger las compartiera o no. ${ }^{38}$

\subsection{El tránsito cusano desde el principio de plenitud a la analogía del ente}

En efecto, según Inciarte-Llano, Heidegger habría mantenido un doble punto de vista muy paradójico a este respecto. De hecho el primer Heidegger habría objetado que la metafísica creacionista medieval hubiera fomentado un ilimitado uso voluntarista de este mismo principio de plenitud, sin tampoco ya poder justificar donde se debería establecer el término final de este mismo proceso cada vez más globalizador. Sin embargo el segundo Heidegger acabaría reconociendo la presencia de este tipo de dificultades en sus propias propuestas. De hecho el mismo habría concebido el conjunto del «ser de los entes» como el horizonte interpretativo en sí mismo ilimitado que resulta de la simple superposición acumulativa de la propia «existencia» de cada ente y de los correspondientes individuos singulares, al modo escotista, sin que tampoco se pudiera ya delimitar el término final de un proceso que también en su caso sin poderlo evitar se volvía cada vez más voluntarista. ${ }^{39}$

En cualquier caso el Heidegger posterior, según Inciarte-Llano, acabaría reconociendo la aparición de una «diferencia intransitable» entre los «entes» y el denominado «ser de los entes» o entre los individuos singulares y el respectivo concepto universal que pretende unificarlos. En efecto, si se sigue fomentando un uso meramente voluntarista del principio de plenitud tampoco sería posible establecer un límite a este mismo proceso, ni tampoco se podría salvar la distancia

38 A este respecto afirma Heidegger: «En cuanto a la profundización ontológica del problema (del fundamento transcendental de los entes), Descartes queda muy a la zaga de la escolástica, más aún, elude la cuestión. Nulla eius substantiae nominis significatio potest distinte intelligi, quae Deo et creaturas sit communis. (nada de lo significado por el nombre de su substancia se puede inteligir distintamente, respecto de lo que es común a Dios y a las criaturas). Al eludir este problema, Descartes deja sin examinar el sentido del ser involucrado en la idea de substancialidad y el carácter de "universalidad" (transcendentalidad) de esta significación» (Heidegger, ST, pp. 114-115).

39 A este respecto afirman Inciarte-Llano, contraponiendo el uso voluntarista y realista que el cusano propone del principio de plenitud: «Nada es su propio poder, nada - fuera de Dios - es un Posset en el sentido referido. Esto es evidente: en ningún momento somos (y en este sentido también hacemos) lo que podemos ser. $\mathrm{Y}$ esto evidentemente vale en general. Nada agota en cada caso sus propias posibilidades, que en su mayor parte nunca llegan a desplegarse, en contra de lo que supone el (uso voluntarista del) principio de plenitud [...] La cuestión principal es que, en cuanto que cada cosa se conduce respecto de su ser o medida, esto fundamenta una graduación (analógica) [...] que nunca es tan firme como en el caso de una persona» (Inciarte-Llano, MTFM, pp. 270-271). 
ilimitada que se debe establecer entre el punto de partida y el horizonte de expectativas generadas por este mismo proceso. De hecho todavía más tarde, en la posterior filosofía del Ge-stel o de lo ya dado o dis-puesto, o del armazón, también se acabaría produciendo una situación similar. En cualquier caso el último Heidegger acabó considerando de imposible justificación sus anteriores propuestas existenciales de su primera época, dado que generaban una diferencia última en sí misma intransitable, por más ilusiones que uno se quisiera hacer al respecto. ${ }^{40}$

Se establece así una clara diferenciación entre las propuestas de Heidegger y las de Aristóteles. ${ }^{41}$ De hecho Aristóteles en el libro sobre las Categorías habría seguido manteniendo un uso unívoco de la noción de «ente», debido en gran parte al uso voluntarista que todavía habría seguido haciendo del principio de plenitud, al modo como defenderán más tarde escotistas y nominalistas en la filosofía medieval. En este sentido habría defendido en un primer momento una postura realista ingenua respecto de la fundamentación de los universales, como si constituyeran entidades ontológicas efectivamente existentes. En cambio, en los libros de la Metafísica Aristóteles habría pasado a defender un uso mucho más estricto y realista del principio de plenitud, de modo que sólo se aplicaría propiamente en el caso Dios y en los demás casos de un modo análogo, al modo ya explicado. Pero por similares razones, también se habría pasado a defender un realismo hipercrítico respecto del fundamento simplemente análogo o cuasi-análogo de los conceptos universales. Es decir, entre la universalidad de los conceptos y la singularidad de los individuos sólo se podría atribuir un simple fundamento potencial o virtual de naturaleza simplemente análoga o semejante de perfiles mucho más indefinidos. $^{42}$

\subsection{El doble giro análogo-icónico desde «De docta ignorancia» al «De visione Dei»}

Por su parte, Johannes Hoff también ha reconocido el doble uso unívoco y a la vez análogo que la metafísica creacionista habría hecho de la transcendencia del ser, al modo como ya anteriormente le habría denunciado Heidegger. Sin embargo Hoff también ha reconstruido el tránsito paulatino casi inapreciable que se opera en Nicolás de Cusa entre dos posturas muy contrapuestas: por un lado, el inicial giro analógico que le abría permitido justificar la divergencia o contraposición entre los opuestos al modo como se llevó a cabo en el «De docta ignorancia» (1440), a pesar de permanecer unidos entre sí; y, por otro lado, la posterior radicalización icónica o simbólica que le habría permitido justificar en el «De visione Dei» (1453) una diferencia radical última entre el creador y las criaturas, sin que aparentemente se pudiera establecer una semejanza entre ambos extremos, al modo anteriormente establecida por Heidegger. A este respecto ahora se generan en Cusa tres contraposiciones fundamentales, correspondientes a dos épocas muy diferenciadas de su pensamiento, ${ }^{43}$ a saber:

40 Cruz, J.; Prólogo, Gilson, Étienne; Juan Duns Escoto. Introducción a sus posiciones fundamentales, Eunsa, 2007.

41 González, A. L.; «Nicolás de Cusa: La cumbre de la teoría», Servicio de Publicaciones de la Universidad de Navarra, 1993. (2 ed. corr. 1998).

42 A este respecto afirman Inciarte-Llano: «Aristóteles también habla de "cosas", que deben ser unívocas, equívocas y paronímicas (análogas): y lo hace ya en el escrito sobre las Categorías, en el cual —a diferencia de lo que sucede en la Metafísica - todavía cuenta con la unicidad en la cosas, es decir, defiende avant la lettre un punto de vista propio del realismo ingenuo o del realismo de los universales. [...] Se plantea así la cuestión, que ha quedado abierta, acerca de la relación análoga o quasi-análoga, a la que se nos ha quedado reducida la relación ente los individuos, por una parte, y especies y géneros, por otra, como consecuencia de una relación de re unívoca» (Inciarte-Llano, MTFM, pp. 278-279).

43 Brague, R.; En medio de la Edad Media. Filosofías medievales en la cristiandad, el judaísmo y el Islam, Herder, Barcelona, 2014. 
a) La creciente separación analógica entre la razón y la fe. Se trata del problema focal o central del propio saber sapiencial, al modo como en su caso se habría defendido en «De docta ignorancia». De este modo el cusano habría introducido una articulación analógica entre la vía negativa, afirmativa y de la eminencia; es decir, una vía finitista e infinitista, para alcanzar un efectivo conocimiento de Dios. O en la contraposición analógica que también se establece entre la ciencia filosófica y la teología o liturgia revelada, como ahora se las prefiere denominar. Con el agravante de que en el «De docta ignorancia» acabaría predominando un contra-movimiento iconoclasta, que paradójicamente seguirían reclamando con igual fuerza su pertenencia al legado cristológico cristiano. ${ }^{44}$

b) El uso metafísico analógico del concepto moderno de espacio y de autonomía que haría acto de presencia por primera vez en el De Visione Dei. ${ }^{45}$ Se toma como punto de partida en este caso la capacidad que tiene la mirada humana de invertir la perspectiva personal, pudiéndole dar una preferencia en su lugar al punto de vista de los demás interlocutores en vez de al propio. Pero algo similar sucede al establecer una contraposición entre la fe y la razón, o entre el oído y la visión, con la subsiguiente generación de miles de perspectivas cada vez más dispares, aunque en principio todas convergen hacia un foco común y estén llamadas a entenderse entre sí. Aparece así la coincidencia de los opuestos como estrategia a seguir en la nueva Era humanista futura que aún está por venir, al modo anteriormente planteado por Duns Escoto. De todos modos Tomás de Aquino ya habría utilizado anteriormente este mismo poder de inversión o reversión que ahora presenta la imagen percibida en perspectiva para proponer a su vez una alternativa de tipo realista; es decir, una visión de la imagen donde el acto intencional de la visión se debe terminar acoplando teleológicamente al tipo de actualidad asignada al objeto, en la medida que ambos contribuyen a configurar el orden armónico de la Creación. ${ }^{46}$

c) La ontología icónica o simbólica subyacente al deseo de saber, también en su caso aplicado al cuerpo de Cristo en el «De visione Dei». Cusa justificó así la infinita distancia existente entre Dios y cada cosa en particular, sin ser ello óbice para, en un momento posterior, reconocer al modo tomista la estrecha interacción y la inmediatez estrictamente icónica o simbólica existente entre ambos extremos. Dios aparece así como el «Ningún otro» infinito y en sí mismo incomunicable, aunque a su vez se hace presente reafirmándose como el constituyente interior más nuclear del corazón finito humano. Al menos así lo ha hecho notar el movimiento ortodoxia radical promovido inicialmente por Milbank, Pickstock y Ward. ${ }^{47}$ Se localizan así dos manifestaciones irreductibles del amor, a saber: o bien se admite la capacidad de reconocimiento del amado, ya se trate de Cristo o de cualquier otro semejante; o bien se advierte la absoluta incapacidad por parte del hombre para alcanzar dicho don, salvo que se recurra a un procedimiento icónico o simbólico, como ahora sucede respecto del absolutamente Ningún otro. ${ }^{48}$

44 Andrews, James; Hermeneutics and the Church. In Dialogue with Augustine, Notre Dame University Press, Notre Dame (IN), 2013.

45 González, A. L.; «Nicolás de Cusa: La visión de Dios», Eunsa, Pamplona, 1994. (2ª ed. 1996; $3^{\text {a }}$ ed. 1999; $4^{\text {a }}$ ed. 2001; $5^{\text {a }}$ ed. rev. 2007; $6^{\text {a }}$ ed. 2009).

46 Novotný, Daniel D.; 'Ens rationis' from Suárez to Caramuel. A Study in Scholasticism of the Baroque Era, Fordham University Press, New York, 2013.

47 Milbank, J.; Pickstock, C.; Ward, G.; Radical Ortodoxy. A New Theology, Roudledge, London, 1999.

48 Cf. Soskice, J. M. (eds.); «Creation 'Ex Nihilo' and Modern Theology», Modern Theology, vol. 29, Issue 2, April 2013, Wiley Blackwell, West Sussex, 2013. 


\section{CONCLUSIÓN: ¿ANALOGÍA TOMISTA, VOLUNTARISMO ESCOTISTA O PLENITUD CUSANA?}

Para concluir una reflexión crítica. Tanto Inciarte y Llano, como Hoff, llevan a cabo una defensa de la metafísica creacionista de Nicolás de Cusa después de las críticas formuladas por Heidegger a este respecto. Por su parte sus propuestas se formulan siguiendo procedimientos complementarios, pero recurriendo a tradiciones de pensamiento muy distintas. Al menos así sucede ahora con el principio de plenitud aristotélico-tomista y de analogía de origen más bien neoplatónico, aunque al final ambos se demuestran como internamente complementarios. A este respecto las propuestas de Inciarte-Llano y las de Hoff acabarían siendo convergentes, a pesar de haber seguido estrategias muy distintas. Inciarte y Llano consideran prioritario la recuperación de una fundamentación cusana a partir del uso analógico del principio de plenitud, considerando que aquellos ulteriores desarrollos decisionistas y finitistas ya tienen un valor menos relevante desde un punto de vista metafísico. En este sentido consideran que la metafísica creacionista cusana resaltó la diferencia radical última existente entre el Creador y las criaturas, defendiendo una postura fundamentalmente tomista y aristotélica, sin perjuicio de las posteriores relaciones de analogía que también pueden establecerse entre ellas. En cambio Hoff considera prioritario la necesidad de abrirse a una posible filosofía del futuro donde se logre un pleno desarrollo de la analogía del ente, de modo que aquellos otros desarrollos decisionistas y en sí mismos finitistas de carácter más bien escotista puedan quedar integrados en un principio de plenitud cusano verdaderamente creacionista. En este sentido se resaltan inicialmente las relaciones de semejanza que el cusano establece entre el Creador y las criaturas, desde una postura fundamentalmente patrística y neoplatónica, con independencia de la diferencia radical última que se establece entre ellos. En cualquier caso se trata de dos posibles estrategias a seguir a la hora de abordar los nuevos retos que el primer Heidegger planteó en Ser y tiempo a una metafísica creacionista, ya sea de tipo tomista, escotista o estrictamente cusana, sin que haya una real incompatibilidad entre ellas. Por su parte, lo que en el fondo se dirime es una cuestión de oportunidad, a saber: cual de las dos estrategias resulta más oportuna a la hora de abordar las críticas formuladas por Heidegger y que la posmodernidad posterior ha seguido planteando a la estrategia de fundamentación seguida por la metafísica creacionista medieval. En cualquier caso en este artículo no se han abordado los retos que, según Heidegger, también deberían ser abordados por una metafísica creacionista, que quisiera ser verdaderamente consecuente consigo misma. De todos modos se trata de un segundo problema que tendrá que ser analizado más pormenorizadamente en otro momento. ${ }^{49}$

Fecha de recepción: día 7 de febrero de 2016

Fecha de aceptación: día 9 de septiembre de 2016

49 A este respecto afirman Inciarte-Llano: «El ser creado es precisamente ser sólo en la medida que es ser creado. El ser se predica analógicamente de la criatura de un modo intrínseco, no porque Dios y la criatura convengan en un ser común - en ese ser masa, del que hemos hablado en este libro - sino porque el ser creado no se suma a lo divino: sólo es ser en cuanto intrínsicamente dependiente del ser divino» (Inciarte-Llano, MTFM, p. 354). 